\title{
UMA ANÁLISE PSICOSSOCIAL DOS ALUNOS DO CURSO DE ENGENHARIA ELÉTRICA DA UNIVERSIDADE FEDERAL DE SANTA MARIA NO PERÍODO DE ISOLAMENTO SOCIAL
}

\author{
Artur Hnerique Fernandez da Silva Machado ${ }^{1}$ - ahfernandez94@ gmail.com \\ Laira Milena Moraes Tomé1 - laira.moraes12@gmail.com \\ Luis Augusto ${ }^{1}$ - luismaugustos@gmail.com \\ Rafael Horvath ${ }^{2}$ - rafael.horv@gmail.com \\ Tainá Lersch ${ }^{1}$ - tainalersch.ufsm@ gmail.com \\ Guilherme Buriol ${ }^{1}$ - guilhermeburioll@ gmail.com \\ ${ }^{1}$ Bolsista do Programa de Educação Tutorial (PET) Engenharia Elétrica \\ ${ }^{2}$ Membro do Programa de Educação Tutorial (PET) Engenharia Elétrica \\ Universidade Federal de Santa Maria \\ Av. Roraima, 1000-7 - Camobi \\ CEP 97105-900 - Santa Maria - Rio Grande do Sul
}

Resumo: Aspectos psicossociais são de suma importância para o bem estar de toda e qualquer pessoa, principalmente neste período de pandemia. Dessa forma, o Programa de Educação Tutorial Engenharia Elétrica (PET-EE) da Universidade Federal de Santa Maria (UFSM) elaborou uma pesquisa com os docentes e discentes do curso de engenharia elétrica através de um formulário online. Este, tinha o intuito de coletar e analisar dados sobre o conteúdo repassado aos estudantes, bem como esses estão frente aos problemas causados ou acentuados durante esse período de pandemia. Os dados gerados foram analisados, a fim de gerar um estudo sobre o comportamento dos alunos e uma metodologia de aprendizagem que pudesse amenizar ao máximo os efeitos negativos que afetam esses alunos nesse tempo tão conturbado de isolamento social.

Palavras-chave: Pandemia. Aspectos psicossociais. Metodologia de aprendizagem.

\section{INTRODUÇÃO}

A COVID-19 é uma doença causada pelo vírus Coronavírus, que foi identificado pela primeira vez na cidade de Wuhan na China. Houve uma disseminação muito rápida da doença, evoluindo de uma epidemia para uma pandemia, com uma taxa de letalidade relativamente alta em determinados grupos de pessoas. Estudos mostram que jovens estudantes não são o principal grupo de risco (GÖTZINGER, 2020), mas acabam sendo um vetor para a transmissão do vírus, tornando necessária a suspensão das aulas presenciais em todos os níveis de ensino, com a tentativa de conter a propagação do vírus. O uso da tecnologia para o ensino e aprendizagem foi uma das medidas tomadas pelo Ministério da Educação neste período excepcional, que recomendou às instituições de ensino superior a continuidade das aulas, à distância em plataformas digitais, sendo tal modelo, admitido pela UFSM, com o intuito de compensar os danos causados a comunidade acadêmica devido ao afastamento social.

Tendo em vista essa nova metodologia de ensino vigente nesse período, o PET Engenharia Elétrica, formulou uma pesquisa online com o objetivo de verificar o impacto psicossocial e as dificuldades enfrentadas pelos alunos de Engenharia Elétrica e os docentes desta Instituição. 
Esta pesquisa teve foco no volume de conteúdo repassado aos estudantes durante as aulas neste regime, capacidade de absorção de conteúdo e relação entre eles e análise psicossocial. Segundo Gallassi (2020): “A interrupção abrupta das relações sociais devido a uma pandemia pode provocar um quadro de sofrimento psíquico. As pessoas podem reagir com intensa ansiedade ou medo. A ansiedade e o medo se tornam ainda mais comuns quando a pandemia realmente chega".

\section{JUSTIFICATIVA}

Esta pesquisa foi realizada com o intuito de compreender diferentes aspectos da vida acadêmica do estudante de engenharia elétrica durante o período de isolamento social, consequência do combate à pandemia do coronavírus. Para mensurar a eficiência do regime de exercícios domiciliares (REDE) aplicado pela universidade e também verificar a situação dos alunos no que compete a acessibilidade de aspectos psicossociais.

A UFSM implementou o REDE com o propósito de manter a comunicação entre discentes e docentes. É importante ressaltar que esse regime não se propõe a substituir aulas presenciais ou propriamente EaD já estabelecidas antes da suspensão do semestre letivo. Professores são livres para cobrar presença e avaliação dos alunos que puderem participar, na esperança de poder usar isso para encurtar a recuperação das aulas no período pós isolamento. O REDE possui algumas falhas que o impedem, até então, de ser uma proposta obrigatória, como capacidade do portal Moodle e acesso pleno dos alunos à internet. Este artigo pretende avaliar o entendimento dos alunos quanto a eficiência desse programa.

Aliado a isso, esta pesquisa também procura entender como o período de pandemia está afetando o estilo de vida dos alunos, levando em conta mudanças de rotina, insegurança financeira, agravamento de complicações psicológicas, diminuição do contato e convívio de colegas de aula e problemas familiares. Este trabalho pretende compreender os possíveis impactos destes aspectos no desempenho acadêmico do aluno.

\section{OBJETIVOS}

Com base nos resultados da pesquisa elabora, pretende-se avaliar os impactos causados no ensino-aprendizagem dos alunos, bem como sua origem psicossocial. Bem como, observar quais métodos são mais eficientes pela visão dos alunos, assim como os que não têm funcionado, e levar essa informação aos professores. Conjuntamente a isto, expor aos docentes a situação psicossocial que os estudantes do curso se encontram. Partindo disso, pretendese sugerir uma metodologia que seja mais proveitosa para estudantes e professores, visando uma melhor absorção do conteúdo. Bem como, não sobrecarregar as partes de modo a agravar ou contribuir para o surgimento de problemas psicológicos como ansiedade, desmotivação e depressão.

\section{METODOLOGIA}

Dada a situação de isolamento social em que se encontram estudantes e professores, e buscando um maior alcance da pesquisa, foi elaborado um formulário online, o qual foi encaminhado via e-mail e redes sociais para estudantes e professores do curso de engenharia elétrica. 


\section{Evento On-line}

O formulário, surgiu diante das dificuldades encontradas por cada aluno em sua realidade familiar durante as atividades em REDE. Diante dessas dificuldades encontradas, visando entender também a sobrecarga de conteúdos propostos para as aulas, prejudicando o rendimento acadêmico dos alunos, surgindo assim, alguns transtornos de saúde diante o distanciamento social em decorrência da pandemia e as atividades em REDE.

Os resultados foram analisados quantitativamente, diante das respostas dos entrevistados.

A pesquisa foi realizada de forma anônima, de modo a manter em sigilo a identidade dos participantes. Foi obtida uma amostra de 68 respostas do universo de 198 alunos que compõem o curso de engenharia elétrica da UFSM, possibilitando atingir uma margem de erro de $10,4 \%$ e um nível de confiança de $95 \%$. Além disso, para que a referida pesquisa apresentasse um maior embasamento científico, empregou-se dados de organizações como a Organização Mundial de Saúde (OMS) e a Fiocruz.

\section{RESULTADOS}

Com base nas respostas do formulário aplicado com os discentes e docentes do curso de engenharia elétrica da Universidade Federal de Santa Maria, pode-se observar que uma grande parcela dos alunos apontou que tiveram alterações em suas atribuições/tarefas externas à universidade durante este período de reclusão, fazendo com que coincidisse com o horário das aulas. Apesar dessa amostra não representar a maioria dos alunos, representa uma parcela considerável dos estudantes, totalizando $41,2 \%$, como mostra o Gráfico 1.

Gráfico 1: Alterações nas atribuições/tarefas externas.

"Você teve alterações nas suas atribuições/tarefas externas à UFSM durante este período, de modo a coincidir com o horário de aulas?"

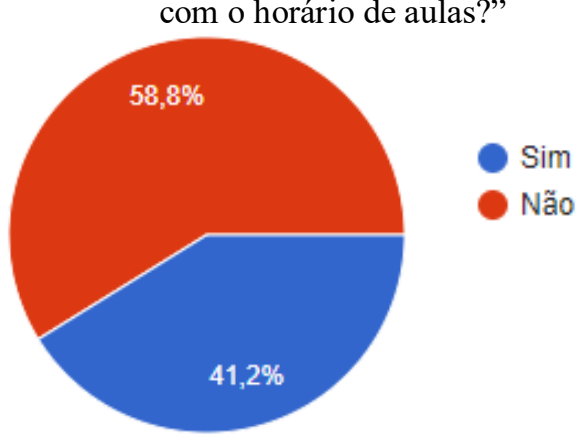

Fonte: Elaborado pelo autor.

Devido à situação do isolamento social em Santa Maria, muitos estudantes voltaram para a cidade de onde vieram, para que passassem esse período de isolamento com suas famílias, isso resulta em uma mudança na rotina e no ambiente de estudo dos estudantes. Além disso, muitos estudantes sofreram com a crise financeira resultante da quarentena, sendo assim, alguns estudantes tiveram que buscar métodos alternativos de ganhar renda, e também, muitos participam das tarefas domiciliares, ou tomam conta de outros membros familiares.

Visando compreender a situação que os discentes estão enfrentando ao utilizar o método de REDE, questionou-se: "Como você avalia o volume de conteúdo, material e informação que está sendo passado via REDE quando comparado ao período normal?". Uma pequena amostra afirmou que em comparação ao regime presencial, o volume de conteúdo está alto, representando $11,8 \% ; 26,5 \%$ afirma que está baixo e 61,8\% afirma que considera adequado, 
como mostrado no Gráfico 2. Consoante a isso, o Gráfico 3 questiona a coerência das atividades propostas pelos professores, em uma escala em que o número 1 corresponde a "nada coerente" e o número 5 a "totalmente coerente". Como pode-se observar, a maior parte dos alunos apontou a coerência dos conteúdos entre 3 e 5, representando $75 \%$ das respostas. Com esses gráficos é possível concluir que os alunos julgam, tanto o conteúdo quanto o volume de informação adequados quando comparados ao ensino-aprendizagem em regime presencial.

Gráfico 2: Avaliação da quantidade de conteúdo.

"Como você avalia o volume de conteúdo, material e informação que está sendo passado em REDE quando comparado ao período normal?"

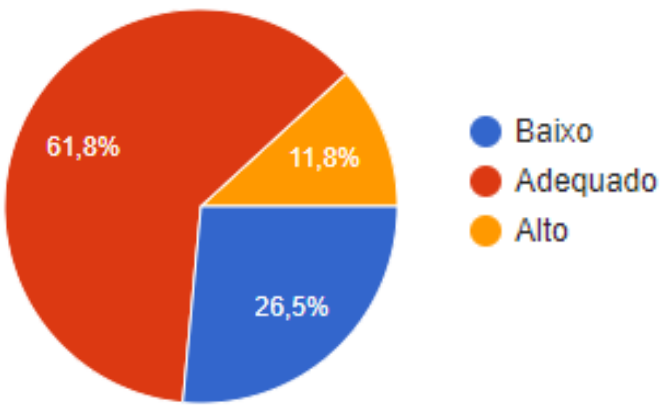

Fonte: Elaborado pelo autor.

Gráfico 3: Coerência das atividades propostas com o conteúdo ministrado.

"Quanto às questões e atividades propostas pelos professores, avalie de 1 a 5 o quanto elas são coerentes com o conteúdo transmitido pelos docentes?"

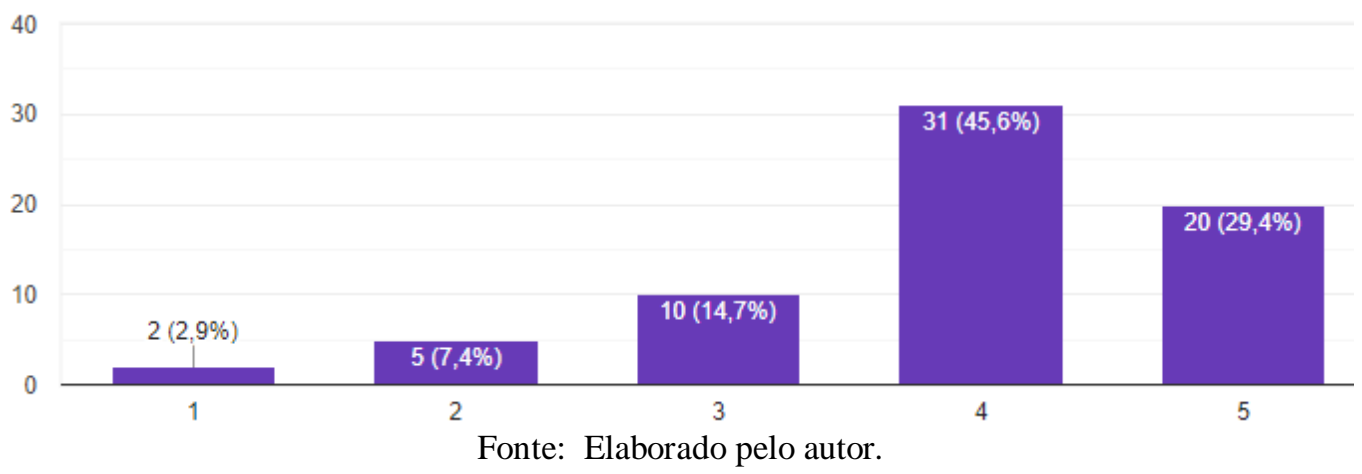

No Gráfico 4, foi pedido que os alunos avaliassem de um a cinco, sendo um como péssimo e cinco como ótimo, o quanto eles estão conseguindo absorver do conteúdo e se estão apresentando uma aprendizagem eficiente da mesma forma que com aulas presenciais. Totalizando 76,4\%, os alunos afirmam que o aprendizado está entre 1 e 3, e apenas $23,5 \%$ afirma que está entre 4 e 5, ou seja, a maior parcela dos alunos não está conseguindo absorver os conteúdos passados e não estão aprendendo de maneira eficiente quando comparado ao método presencial. Isso nos leva a concluir que apesar de a maioria dos alunos julgar que os conteúdos são coerentes, e que o volume de material e informação é adequado, esses não estão sendo absorvidos de maneira satisfatória, de maneira que $88,2 \%$ dos alunos afirmam que seu aprendizado está sendo prejudicado, como mostrado no Gráfico 5.

Gráfico 4: Nível de absorção do conteúdo.

“Avalie de 1 a 5, sendo 1 nada proveitoso e 5 totalmente proveitoso, o quanto você está conseguindo absorver o conteúdo e ter um aprendizado eficiente da mesma forma que teria com aulas presenciais :" 


\section{COBENGE (C) COBENGE 2020

30

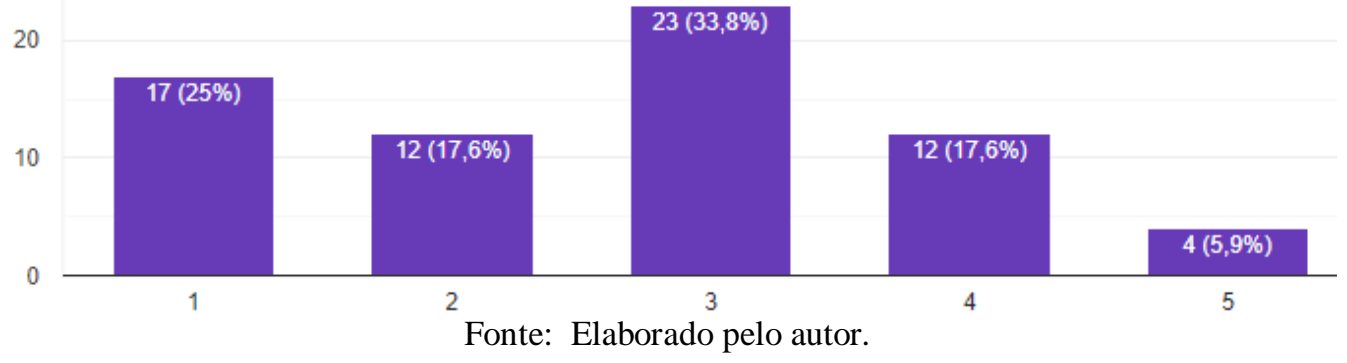

Gráfico 5: Nível de prejuízo do aprendizado.

"Você acredita que esse período de quarentena está, de alguma forma, prejudicando o seu aprendizado?"

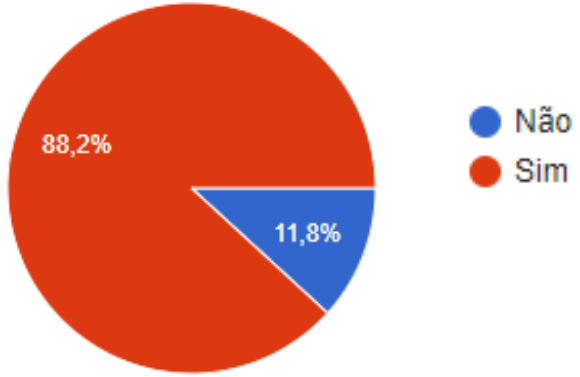

Fonte: Elaborado pelo autor.

Uma pesquisa realizada pelo Diretório Acadêmico (DCE) da UFSM, entre os dias 2 e 10 de abril, com o objetivo de verificar a situação estudantil durante o isolamento social, que obteve 1606 respostas, sendo elas, oriundas de estudantes de 67 cursos da instituição de ensino. Um dos questionamentos apresentados era: "Em relação às atividades à distância, você está conseguindo cumpri-las?”, o Gráfico 6 apresenta o resultado obtido.

Gráfico 6: Consegue cumprir as atividades a distância.

"Em relação às atividades à distância, você está conseguindo cumpri-las?"

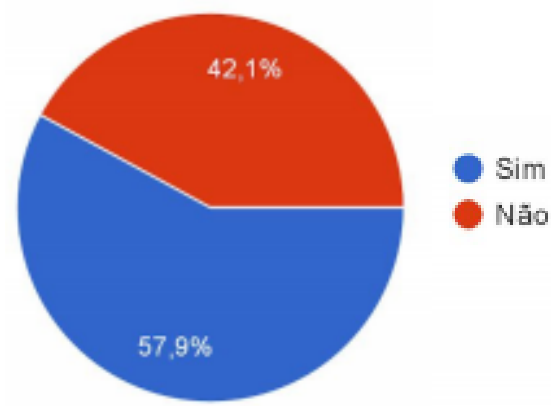

Fonte: DCE.

No Gráfico 6 é possível observar que 42,1\% dos estudantes afirma que não está conseguindo cumprir as atividades propostas no REDE. Logo após, na mesma pesquisa, indaga-se para aqueles que afirmaram que não estão conseguindo acompanhar as aulas, quais são os motivos para esse comportamento. 60,9\% respondeu que não possui condições psicológicas para realizar tais atividades, $40,9 \%$ afirma que o conteúdo disponibilizado não é suficiente para a realização das atividades, $28,7 \%$ afirma que um dos motivos é a necessidade de cuidar de outros membros da família, $25,3 \%$ afirma que a dificuldade de acesso a internet é 
um dos motivos e 11,2\% afirma que não possui aparelhos eletrônicos necessários para acessar as plataformas usadas. Com estes dados, pode-se concluir que a pesquisa realizada pelo Programa de Educação Tutorial PET Engenharia Elétrica apresenta resultados semelhantes à pesquisa realizada pelo DCE, mostrando assim que um número considerável dos estudantes apresenta dificuldades em acompanhar as aulas em REDE e muitas vezes não conseguem absorver os conteúdos de forma plena.

O ensino a distância $(\mathrm{EaD})$ já é uma realidade para muitos universitários, mesmo antes do período de distanciamento social, inclusive com faculdades exclusivamente com esse fim. Em alguns casos, o ensino à distância apresenta vantagens, como a possibilidade do aluno decidir seus horários de estudo, porém, um dos problemas que surge é a falta de interação entre colegas e professores, especialmente em períodos em que o isolamento social contribui para a não proliferação da doença. Sendo assim se torna mais difícil formar um grupo de estudos ou fazer trabalhos em grupo.

O desenvolvimento de aspectos sociais, como liderança, trabalho em equipe, negociação, dentre outros, são muito importantes para a formação dos estudantes, uma vez que estes serão aspectos importantes futuramente no mercado de trabalho. Concordante a isso, o Gráfico 7 apresenta o posicionamento dos alunos a respeito da pergunta:

Gráfico 7: Prejuízo no aspecto social.

"O quanto você acredita que as aulas EAD prejudicam o desenvolvimento de aspectos sociais, sendo 1 nada e 5 muito?"

30

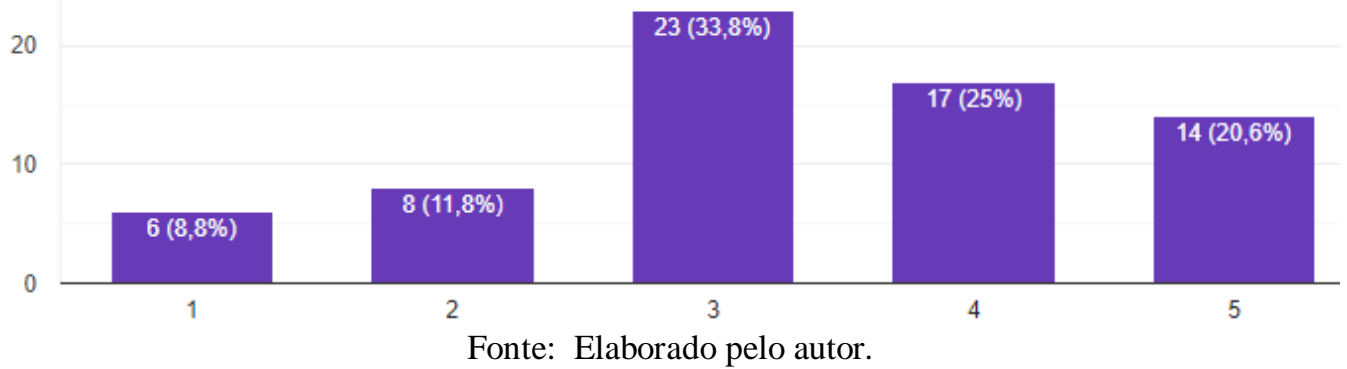

Nesse gráfico, o número um representa "menor grau de prejuízo" e o número cinco é o "maior grau de prejuízo". É perceptível que a maioria dos alunos notam que neste período o desenvolvimento de aspectos sociais vem sendo prejudicado, e é necessário propor alguma solução para amenizar isso. Também é importante ressaltar que nesse período de pandemia casos de transtornos de saúde tendem a surgir, ou mesmo os casos já existentes agravarem-se. Segundo a Fundação Oswaldo Cruz (FIOCRUZ, 2020): "Estima-se, que entre um terço e metade da população exposta a uma epidemia pode vir a sofrer alguma manifestação psicopatológica, caso não seja feita nenhuma intervenção de cuidado específico para as reações e sintomas manifestados".

O gráfico 8 representa a resposta dos alunos à pergunta: "Este período desenvolveu ou acentuou transtornos de saúde, tais como ansiedade, depressão, síndrome do pânico, ou ainda problemas familiares, para você (de maneira que o aprendizado fique prejudicado)?". Praticamente metade dos alunos consultados responderam de forma afirmativa, o que é o esperado pois de acordo com diretor geral da OMS, T. Ghebreyesus (2020): "O impacto da pandemia na saúde mental das pessoas já é extremamente preocupante”. 
Gráfico 8: Acentuação de transtornos de saúde.

"Este período desenvolveu ou acentuou transtornos de saúde, tais como ansiedade, depressão, síndrome do pânico, ou ainda problemas familiares, de maneira que o aprendizado fique prejudicado?”

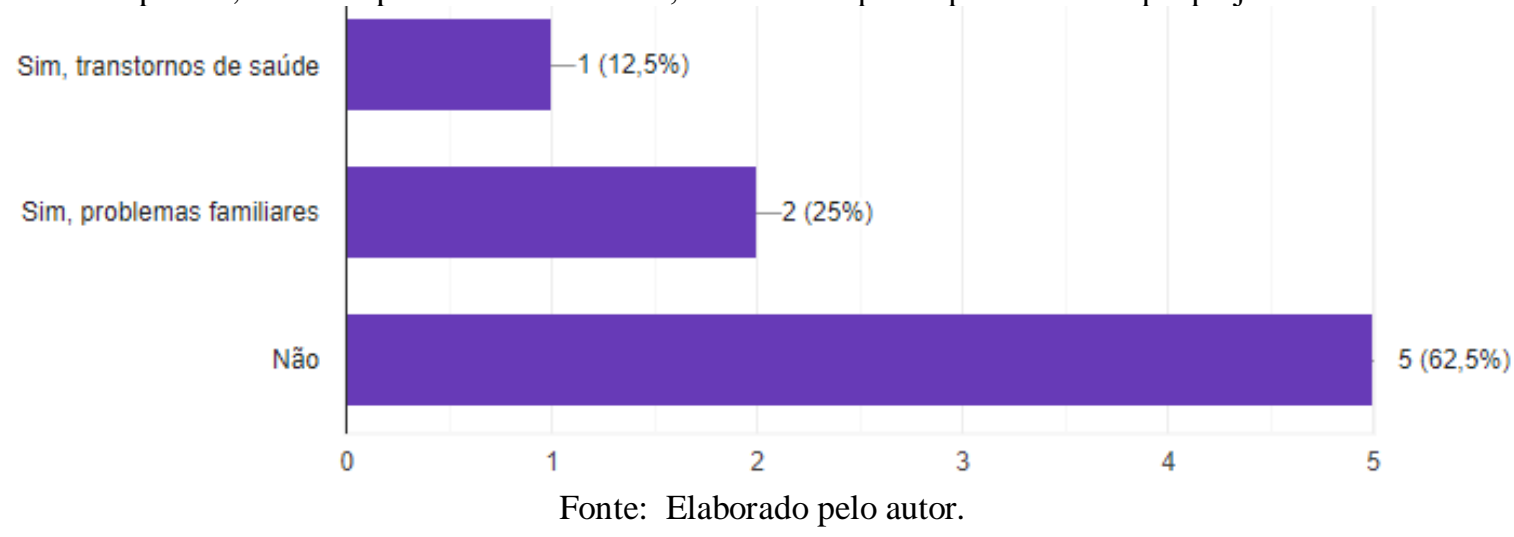

Em vista dos problemas causados, uma possível solução para a redução de riscos a saúde mental dos alunos, bem como para que estes tenham um melhor aprendizado, seria a criação, por parte dos professores e gestores do curso, de uma metodologia onde os alunos consigam absorver os conteúdos que estão sendo trabalhados, para assim amenizar frustrações. Abaixo consta um comentário deixado por um aluno referente à metodologia adotada por alguns professores.

"Não gosto do método que alguns professores estão adotando de simplesmente mandar um material para lermos (livros, artigos e etc) e depois pedir para fazermos um resumo ou uma pequena lista de exercícios. Acredito que assim o nosso estudo fica muito prejudicado pois deixamos de ter a visão de uma pessoa com mais experiência no assunto, além de ser extremamente frustrante estudar sozinho e não sentir que os estudos estão rendendo."

Visando entender quais os métodos de ensino que os docentes julgam mais adequados para o ensino em REDE, o Gráfico 9 apresenta a pergunta "Quais os métodos que você acha que estão sendo mais eficientes neste momento". Nesta questão, era possível selecionar quantas opções fossem necessárias. Já o Gráfico 10, é referente a pesquisa realizada com os docentes da universidade e refere-se a metodologia adotada pelos professores neste período.

Gráfico 9: Métodos mais eficientes para o aprendizado.

"Quais os métodos você acha que estão sendo mais eficientes nesse momento?"

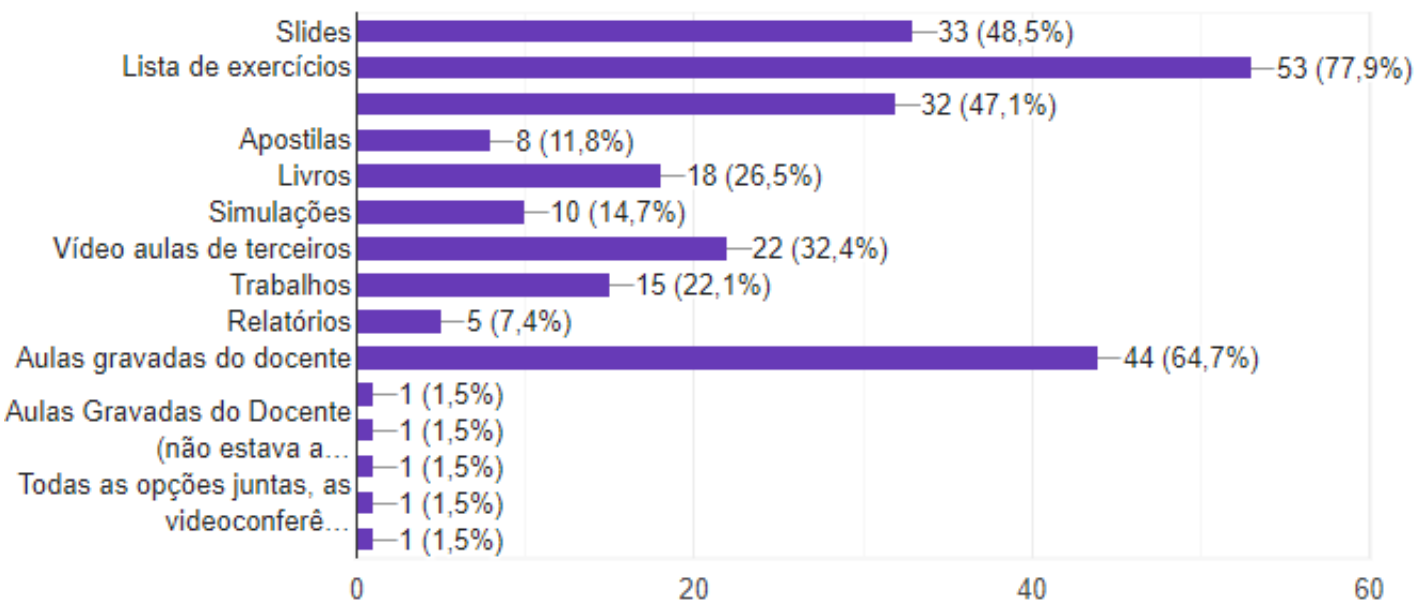




\section{Evento On-line}

Fonte: Elaborado pelo autor.

Gráfico 10: Métodos mais eficientes para o aprendizado.

"Em meio a este período, qual metodologia didática você decidiu adotar?"

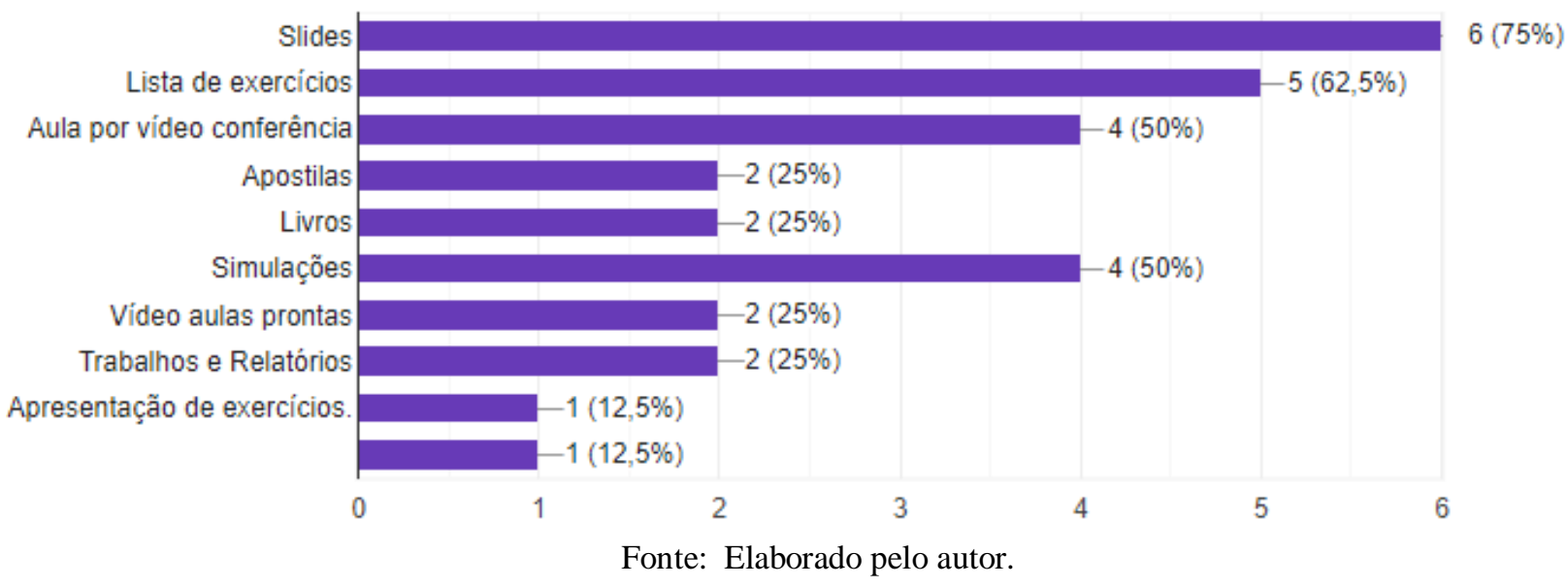

Tendo como base os Gráficos 9 e 10, propõe-se a seguinte metodologia: Aulas gravadas e disponibilizadas aos alunos, podendo ser do próprio docente e/ou de terceiros. Assim, os estudantes poderiam acompanhar as aulas sem dificuldade por conta do horário e poderiam reproduzi-la quantas vezes necessárias até haver a melhor compreensão possível. Após isso os professores poderiam disponibilizar o material utilizado por eles (livros, apostilas, slides, entre outros) para que seja possível a leitura pelos alunos que não entenderam o conteúdo proposto, bem como para os que desejam se aprofundar mais.

Junto a esse material poderia ser proposta uma série de atividades relacionadas ao assunto para que os discentes possam praticar e relacionar a parte teórica com a prática, de forma a estimular os alunos a buscar compreender o conteúdo passado. Conjuntamente a isso, poderiam ser realizadas videoconferências onde seria disponibilizado um certo tempo para solucionar dúvidas sobre os exercícios e conteúdos.

Essa metodologia auxiliaria os estudantes que acreditam apresentar um baixo rendimento, visto que a utilização de questões forneceria uma direção para os discentes, bem como a compreensão dos conteúdos seriam facilitados devido a um maior auxílio dos professores, reduzindo o tempo demandado para o estudo de determinadas matérias, por consequência haveria um menor acúmulo de conteúdo. Bem como, seria uma metodologia condizente com o que as metodologias adotadas pelos professores, uma vez que a maioria já utiliza listas de exercícios, aulas por videoconferência, e materiais de apoio, como livros, slides e apostilas, como mostra o Gráfico 10.

\section{CONSIDERAÇÕES FINAIS}

A partir da pesquisa realizada pelo Programa de Educação Tutorial PET engenharia elétrica, bem como, baseado nos resultados das pesquisas da Fiocruz e OMS, podemos constatar que muitos alunos apresentam dificuldade ao se adaptar a metodologia de ensino em REDE. Isso ocorre, pois, mesmo que esses julguem que a carga de conteúdo é semelhante a do ensino presencial, nota-se uma baixa compreensão desse conteúdo por parte dos estudantes, como mostra a pesquisa. Tal fato ocorre por conta do ensino a distância não ser comum aos discentes, bem como aos docentes, onde ambos precisaram mudar sua rotina para encaixar-se 
no novo regime de estudos. Nessa situação houve aumento ou surgimento de alguns fatores, tais como transtornos de saúde, contratempos familiares, entre outros problemas psicossociais. Além disso, o ensino em REDE, juntamente ao isolamento social, diminui as interações sociais dos estudantes, assim, algumas das habilidades desenvolvidas através do convívio social foram prejudicadas.

Parte do estresse gerado nesse período se deve, a metodologia empregada, visto que esta não está adaptada para o ensino em REDE, isso dificulta a compreensão do conteúdo por parte dos alunos levando a frustrações, desânimo, e baixo rendimento Assim, para tentar minimizar esse empecilho, propõem-se que seja utilizada uma metodologia que reúna os métodos de ensino que os discentes, de acordo com a pesquisa, apresentaram maior facilidade de aprendizagem. Dessa forma, os estudantes seriam mais estimulados nos seus estudos e teriam mais contato com seus colegas e docentes.

\section{REFERÊNCIAS}

ADAIME, M. B. INFORMATIVO A RESPEITO DO DESENVOLVIMENTO DAS AULAS DURANTE O PERÍODO DE REGIME DE EXERCÍCIOS DOMICILIARES ESPECIAIS (REDE). Disponível em: https://www.ufsm.br/pro-reitorias/prograd/wpcontent/uploads/sites/342/2020/04/Informativo_Prograd_abril_2020.pdf. Acesso em: 26 de maio de 2020.

GALLASSI, A. D. O Impacto Psicossocial do Isolamento Social na Universidade de Brasília. Disponível em: http://repositoriocovid19.unb.br/repositorio-projetos/o-impactopsicossocial-do-isolamento-social-na-universidade-debrasilia/?utm_source=rss\&utm_medium=rss\&utm_campaign=o-impacto-psicossocial-doisolamento-social-na-universidade-de-brasilia. Acesso em: 21 de maio de 2020.

GHEBREYESUS, T. A. ONU destaca necessidade urgente de aumentar investimentos em serviços de saúde mental durante a pandemia de COVID-19. Disponível em: https://www.paho.org/bra/index.php?option=com_content $\&$ view=article\&id=6170:onudestaca-necessidade-urgente-de-aumentar-investimentos-em-servicos-de-saude-mentaldurante-a-pandemia-de-covid-19\&Itemid=839. Acesso em: 21 de maio de 2020.

NOAL, D. S. Saúde Mental e Atenção Psicossocial na Pandemia COVID-19. Disponivel em: $\quad$ https://www.fiocruzbrasilia.fiocruz.br/wp-content/uploads/2020/04/Sa\%c3\%badeMental-e-Aten\%c3\%a7\%c3\%a3o-Psicossocial-na-Pandemia-Covid-19recomenda\%c3\%a7\%c3\%b5es-gerais.pdf. Acesso em: 22 de maio de 2020.

GÖTZINGER, F. et al. COVID-19 in children and adolescents in Europe: a multinational, multicentre cohort study. The Lancet. Child \& adolescent health vol. 4,9 (2020): 653-661. doi:10.1016/S2352-4642(20)30177-2 


\title{
A PSYCHOSOCIAL ANALYSIS OF THE STUDENTS OF THE ELECTRICAL ENGINEERING COURSE AT THE FEDERAL UNIVERSITY OF SANTA MARIA IN THE PERIOD OF SOCIAL ISOLATION
}

\begin{abstract}
Psychosocial aspects are of paramount importance for the well-being of each and every person, especially in this pandemic period. Thus, the Electrical Engineering Tutorial Education Program (PET-EE) of the Federal University of Santa Maria (UFSM) prepared a survey with the teachers and students of the electrical engineering course through an online form. This had the intention of collecting and analyzing data about the content passed on to students, as well as they are facing the problems caused or accentuated during this pandemic period. The data obtained were analyzed in order to generate a study on the students' behavior and a learning methodology that could minimize the negative implications that affect these students in this very troubled time of social isolation.
\end{abstract}

Keywords: Pandemic. Psychosocial aspects. Teaching learning. 